\title{
Investigating the Role of Cognitive Feedback in Practice-Oriented Learning for Clinical Diagnostics
}

Citation for published version (APA):

Yuan, B., Wang, M., van Merrienboer, J., Tao, X., Kushniruk, A., \& Peng, J. (2020). Investigating the Role of Cognitive Feedback in Practice-Oriented Learning for Clinical Diagnostics. Vocations and Learning, 13(1), 159-177. https://doi.org/10.1007/s12186-019-09234-z

Document status and date:

Published: 01/04/2020

DOI:

10.1007/s12186-019-09234-z

Document Version:

Publisher's PDF, also known as Version of record

Document license:

Taverne

Please check the document version of this publication:

- A submitted manuscript is the version of the article upon submission and before peer-review. There can be important differences between the submitted version and the official published version of record.

People interested in the research are advised to contact the author for the final version of the publication, or visit the DOI to the publisher's website.

- The final author version and the galley proof are versions of the publication after peer review.

- The final published version features the final layout of the paper including the volume, issue and page numbers.

Link to publication

\footnotetext{
General rights rights.

- You may freely distribute the URL identifying the publication in the public portal. please follow below link for the End User Agreement:

www.umlib.nl/taverne-license

Take down policy

If you believe that this document breaches copyright please contact us at:

repository@maastrichtuniversity.nl

providing details and we will investigate your claim.
}

Copyright and moral rights for the publications made accessible in the public portal are retained by the authors and/or other copyright owners and it is a condition of accessing publications that users recognise and abide by the legal requirements associated with these

- Users may download and print one copy of any publication from the public portal for the purpose of private study or research.

- You may not further distribute the material or use it for any profit-making activity or commercial gain

If the publication is distributed under the terms of Article $25 \mathrm{fa}$ of the Dutch Copyright Act, indicated by the "Taverne" license above, 


\title{
Investigating the Role of Cognitive Feedback in Practice-Oriented Learning for Clinical Diagnostics
}

\author{
Bei Yuan ${ }^{1,2} \cdot$ Minhong Wang ${ }^{3,2}$ (D) Jeroen van Merriënboer ${ }^{4} \cdot \mathrm{Xu} \mathrm{Tao}^{5}$. \\ Andre Kushniruk ${ }^{6}$. Jun Peng ${ }^{7,2}$
}

Received: 20 November 2018 / Accepted: 24 September 2019/Published online: 23 October 2019

(C) Springer Nature B.V. 2019

\begin{abstract}
Reflection plays an important role in medical students' ability to develop diagnostic competence through practice with clinical cases. However, it is not easy for students to develop expert-like performance through self-reflection alone; conversely, seeking feedback from experts constantly in practice is impractical. This study investigates the design and effects of computer-based cognitive feedback in practice-oriented learning in an online system. The system allows learners to work with simulated cases and self-review and reflect on their diagnostic processes that the system captures visually. Moreover, the system provides learners with feedback about the gap between their performance and expert performance on a set of key components of the diagnostic task, i.e., selecting clinical examinations, making intermediate judgements, and reaching diagnostic conclusions. The findings show that cognitive feedback on task performance can reduce learners' anxiety and frustration while working with complex tasks. Moreover, by providing feedback on learners' performance on a set of key components of the task, the proposed approach has shown promising effects on improving learners' diagnostic performance. Compared with its effects on learners' diagnostic conclusions, the approach is more effective in enhancing learners' performance when selecting clinical examinations and making intermediate judgements, both of which may improve learners' understanding of the mechanism underlying the diagnostic process.
\end{abstract}

Keywords Reflective practice $\cdot$ Cognitive feedback $\cdot$ Clinical diagnostic reasoning . Computer-supported learning $\cdot$ Emotion

Minhong Wang

magwang@hku.hk

Extended author information available on the last page of the article 


\section{Introduction}

Clinical diagnosis is the core of medical expertise (Elstein et al. 1978). Medical education places great emphasis on developing students' diagnostic competence. Traditionally, medical students developed clinical diagnostic competence by working alongside experts on authentic cases in clinical clerkships and rotations. However, the opportunities to improve students' diagnostic performance in such contexts may be limited by low patient variability, insufficient supervision, and irregular and inconsistent feedback (Schmidt and Mamede 2015). In recent decades, clinical reasoning and problem-based learning curricula (Barrows 1996) have been widely promoted, where students are presented with authentic cases and engaged in problem-solving and critical thinking activities to develop their problem-solving competence and consolidate and extend their subject knowledge (Kassirer 2010). More recently, educators have developed computer simulations and virtual reality techniques as additional alternatives to clinical learning (Ruiz et al. 2006). For example, virtual patients, which take the form of interactive computer-based clinical scenarios, can be used to facilitate and assess the development of students' clinical reasoning (Cook and Triola 2009).

Diagnosing a clinical case involves a complex process of searching for problemrelevant information in multiple aspects, linking that information with subject knowledge, reasoning with multiple interactive elements, and making diagnostic judgements and decisions. Such complexity may generate a heavy cognitive load for learners (Van Merriënboer and Sweller 2010), especially for novice learners who have not yet developed cognitive schemas and reasoning strategies to cope with complex diagnostic processes. Accordingly, studies have shown that students in their senior year of medical school undergoing intensive immersion in clinical practice tend not to meet expectations in terms of their diagnostic performance (Williams et al. 2011).

In the broader context of higher education (Boud and Walker 1990; Boud and Molloy 2013), reflection and feedback have been recognised as two important methods of practice-oriented learning particularly in clinical settings (Branch and Paranjape 2002). According to experiential learning theory, reflection on practice is crucial to practice-oriented learning: it enables learners to identify gaps in their knowledge and skills, bridge the gap between knowledge and practice, and integrate new learning with existing understanding, a process that has also been called reflective practice (Dewey 1938; Schön 1983; Moon 1999). However, with limited experience and skills in clinical diagnosis, novices may take a long time to develop expert-like performance through self-reflection. Conversely, if a task is too complex, learners may feel anxious and frustrated, which may impede performance (Schutz and DeCuir 2002). In such contexts, expert guidance or feedback is crucial to novices' reflective practice, especially in clinical settings (Kassirer 2010; Norman 2005).

\section{Learning through Reflection}

Learning through reflection on practice (i.e., reflective practice) with clinical cases is largely a process of experiential learning. Research highlights that the outcomes of experiential learning depend not only on engagement in practice, but also, and perhaps more importantly, on reflection on that practice (Dewey 1938; Kolb 1984). Reflection, the process of making sense of experience, is essential for learning through practice 
(Schön 1983; Moon 1999) and is especially beneficial for learning in complex problem situations, such as clinical diagnosis (Mamede et al. 2008; Mann et al. 2009).

Reflection is generally a non-visible activity. Researchers emphasize the pedagogical importance of making reflective thinking and practice explicit (Delany and Golding 2014; Mann et al. 2009). In doing so, many educators recommend thinking-aloud protocols, which help externalise experts' reasoning processes and analyse novices' performance to support reflection and improvement (Banning 2008; Durning et al. 2011). Mamede et al. (2008) found that incorporating reflection into learning activities in a structured format involving deliberate induction and deduction, testing, openness, and meta-reasoning (Mamede and Schmidt 2004) can positively influence medical students' acquisition of diagnostic competence. Related work reported that scaffolding has a positive impact on the quality of learning by reflection (Boldrini and Cattaneo 2014). Further, recent research demonstrated the promising effects of visualisationbased cognitive maps on scaffolding clinical reasoning learning through visible thinking and reflection (Wu and Wang 2012; Wu et al. 2016).

These findings are consistent with the research on expertise development, which reveals that achieving desired learning outcomes in problem-solving contexts requires deliberate effort with expert support rather than a mere accumulation of experience (Ericsson 2008). The literature on reflective practice in medical education has suggested that guidance and supervision are essential to reflection (Mann et al. 2009; Molloy 2009) and calls for investigations into how novices' performance can be improved through expert support or feedback within reflective practice (Mamede et al. 2012; Wang et al. 2018; Yuan et al. 2016).

\section{Learning through Feedback}

Feedback can be understood as information about one's performance or understanding, which may come from an educator, peer or oneself. Feedback can support reflection and improvement and is considered to be crucial for learning and achievement. Research on feedback has gone beyond mere performance review to consider it a fundamental part of curriculum design (Boud and Molloy 2013). There is general agreement that feedback should be ongoing and iterative (Evans 2013). In particular, researchers have identified dialogic feedback processes as a sustainable method for student-centred or self-regulated learning, where feedback is regarded as continuous dialogue and iterative interaction between students and teachers (Ajjawi and Boud 2018; Carless and Boud 2018). To accomplish this, it is important to help students make sense of the feedback they receive and use it to enhance learning and achievement; this entails the development of feedback literacy (Carless and Boud 2018; Sutton 2012). In medical education, researchers have explored educational alliances as a lens to reframe feedback processes, from information transmission to negotiation and dialogue between participants, who seek a shared understanding of performance, standards, and action plans (Telio et al. 2015).

In the context of practice-oriented learning with complex authentic tasks, feedback is regarded as an essential part of the learning experience. Feedback provides a scaffolding for complex problem-solving tasks and reduces the uncertainty of task performance (Shute 2008). For example, the Four-Component Instructional Design (4CID) model, which involves learning tasks, supportive information, procedural information, and 
part-task practice, has been widely used for teaching and learning with complex tasks in authentic contexts (Van Merrienboer and Kirschner 2018). While implementing the 4CID model in learning with clinical reasoning tasks, researchers emphasised the importance of providing valid and timely feedback on task performance (Postma and White 2015).

Similarly, it is noted that feedback's expected benefits derive from the expertise and credibility of its source, in addition to learners' goals and motives and the learning contexts (Bok et al. 2013). Many studies involve experts providing feedback on performance as a form of expert support or high-quality feedback based on reliable and valid sources (Butler and Winne 1995; Eva and Regehr 2005; Van Merrienboer and Kirschner 2018). However, seeking feedback from experts constantly in practice is impractical (Archer 2010; Henderson et al. 2010). With the support of information and communication technologies, computer-enabled approaches have become increasingly common as a support for practice-oriented learning. Many of these approaches involve simulated cases and facilitate the timely and convenient communication of computerbased feedback through the analysis of learning logs and digital traces based on relevant knowledge (Bordage 1999; Carless and Boud 2018; Chiu et al. 2010; Wigton et al. 1990). Researchers have reported positive effects of such computerbased feedback on students' motivation and emotional engagement; however, very few studies relate these effects directly to performance (Evans 2013). Existing approaches have focused on the inclusion of feedback, with little attention to helping learners to achieve expert performance and improving learners' understanding of the mechanism driving the complex task. It remains unclear how high-quality feedback can be designed in a way that leads to desired performance towards expertise development. In medical education, existing studies on feedback have generally focused on curricular approaches involving feedback for learners; there is a need for further study of highquality recommendations for feedback (Bing-You et al. 2017; Telio et al. 2015).

\section{Feedback and Emotion}

Feedback is found to have two types of important features, cognitive and affective (Nelson and Schunn 2009). Cognitive features describe information about the quality of someone's performance or understanding, whereas affective features seek to influence a person's affective and motivational experience by using affective language (e.g., criticism, praise, mitigating). While cognitive and affective features are often integrated in feedback, most feedback research has focused on cognitive features, which can be called cognitive feedback. Cognitive feedback may include evaluative aspects (e.g., verification, problem identification, summary statement), informative aspects (e.g., the source or location of the problem, explanation, hint, solution), and metacognitive aspects (e.g., use of strategies, progress toward a desired goal) (Evans 2013; Nelson and Schunn 2009; Shute 2008).

Cognitive features of feedback are expected to most strongly influence performance and understanding, and affective features are expected to most strongly affect agreement with the feedback; cognitive features may also influence agreement, indirectly through improved performance and understanding (Nelson and Schunn 2009). Similarly, many researchers reported that feedback on understanding and performance (i.e., cognitive feedback) has positive effects not only on improving understanding and 
task performance but also on improving affective experience such as emotional engagement and motivation (e.g., Azevedo and Bernard 1995; Corbalan et al. 2009; Keller 1983; Vollmeyer and Rheinberg 2005). It is agreed that timely feedback sustains motivation. Feedback on understanding and performance can facilitate scaffolding and monitoring of learning processes, which affect intrinsic motivation in a positive way.

Furthermore, research indicates that learners' cognitive and affective experiences are closely intertwined (Phelps 2006). Emotions have a strong influence on motivation and learning performance, especially when learning involves complex subjects or tasks (D'Mello \& Graesser, 2012). If a learning task is too complex, students may feel frustrated, which in turn can increase their anxiety (Schutz and DeCuir 2002). Such negative emotions as anxiety, frustration and hopelessness can impede cognitive processes; in contrast, positive emotions such as enjoyment, confidence and hope can help foster or improve learning (Pekrun et al. 2011). When cognitive feedback on complex task performance is delivered appropriately, it can improve learners' experience by reducing their uncertainty and anxiety (Shute 2008).

\section{The Present Study}

This study aimed to investigate the design and effects of computer-based cognitive feedback for practice-oriented learning of clinical diagnosis in an online environment. The literature highlights the importance of providing feedback on task performance (i.e., cognitive feedback) based on reliable and valid sources (e.g., experts) in learning with complex tasks. In view of the difficulty seeking feedback from experts constantly in practice, computer-based feedback has shown the potential to replace them; however, it remains unclear how high-quality feedback on task performance can be designed in a way that leads to desired performance. Based on previous studies, cognitive feedback may include evaluative, informative aspects, and metacognitive aspects, which reflects a general and inadequate understanding of what constitutes cognitive feedback on learning with complex tasks. Research indicates that cognitive feedback provides a scaffolding for complex problem-solving tasks (Shute 2008). To scaffold learning with complex tasks, existing studies reveal the importance of making explicit the complex task process to foster visible thinking, reasoning and reflection (Delany and Golding 2014; Peng et al. 2019; Wang et al. 2018). Accordingly, the feedback approach proposed in this study is featured by externalizing the key components of the complex diagnostic task (i.e., selecting clinical examinations, making intermediate judgements, and reaching diagnostic conclusions) and providing learners with feedback on their task performance with respect to these key components. In particular, learners are provided with feedback about the gap between their own performance and expert performance on the key components of the diagnostic task.

To examine the effects of the proposed feedback approach, we conducted an empirical study with medical students. The participants practiced with simulated cases through an online system, which could capture and visually represent learners' diagnostic processes back to them to facilitate self-review and reflection. Moreover, the proposed feedback approach was incorporated into the learning system, i.e., using computer-based cognitive feedback to help students reflect on how their performance differed from the expert's during the practice. We expected that with the support of cognitive feedback, students would improve their performance in clinical diagnosis. We 
also expected cognitive feedback to have a positive impact on students' emotions during the learning process.

We therefore examined the following hypotheses.

1. Cognitive feedback will have a positive effect on students' clinical diagnostic performance after practising with clinical cases.

2. Cognitive feedback will have a positive effect on students' emotions while practising with clinical cases.

\section{Method}

We adopted a pretest-posttest control group design, one of the most extensively used methods in clinical research. There were two reasons for adopting this method. First, to facilitate comparison between the experimental and control groups, we administered the pretest to evaluate whether there were any differences between the two groups in terms of subject knowledge and diagnostic performance prior to the treatment. Second, to investigate the effects the intervention (cognitive feedback) on performance and affect, we administered a posttest to examine differences between the two groups in terms of diagnostic performance and emotional experience after the treatment.

The experimental group used the proposed learning system with cognitive feedback and the control group used the same learning system but without cognitive feedback; the expert's summary of each case was provided to both groups in due course. The diagnostic process was designed to mirror clinical encounters; learners were given incomplete information about a case and had to collect further information by selecting clinical examinations and making intermediate judgements over several rounds before reaching a diagnostic conclusion.

\section{Participants}

The study received ethical approval from the Human Research Ethics Committee of the researchers' university (No. EA080113). G*Power (version 3.1) was used to compute the sample size required for the control group design based on statistical power of $80 \%$, tails $=$ two, and a medium effect size of 0.8 ; the output suggested the required sample size as 26 for each group. An invitation letter was sent to about 60 Year-4 students enrolled in a medical school at a university in southern China for their voluntary participation in this study. Fifty students gave their informed consent before participating in the study (age range: 20-22; gender: 52\% male, $48 \%$ female). Prior to the experiment, the participants had been exposed to theoretical knowledge about eye diseases, including glaucoma, and problem-based learning experience. The pretest output showed no outliers or extreme scores in the participants' subject knowledge and diagnostic performance. The participants were then randomly assigned to two conditions: 25 to the experimental condition and 25 to the control condition. We adopted a two-step randomization method to ensure gender balance. First, within the 26 males, 13 were randomly selected and assigned to one of the two conditions; then, the remaining 13 males were assigned to the other condition. Second, the 24 females were randomly assigned to the two conditions using the same procedure. 


\section{Learning Materials}

We selected glaucoma diagnosis as the learning subject. Two domain experts with more than ten years' experience in glaucoma diagnosis and treatment assisted in preparing the clinical cases. Eight exemplar cases were used for the study, one for demonstration, five for student practice and two for assessment. All of the cases were selected and adapted from authentic cases, with reference solutions validated by the experts for assessment and to generate cognitive feedback. The learning environment allowed learners to diagnose clinical cases by interacting with virtual patients (see Fig. 1).

As shown in Fig. 1, one female virtual patient states that she had suddenly started experiencing discomfort in her right eye and headaches about one month ago. She did not feel that the symptoms worsened after exercise. The basic eye examinations revealed no other abnormalities and the visual acuity of her right eye was 0.4 . The main part of the screen showed the gonioscopy of her right eye, with the results set to 1.5 CT for the anterior chamber depth and $<1 / 5 \mathrm{CT}$ for the peripheral anterior chamber depth. Aqueous flare (+) was found in the anterior chamber. Based on these results, the learner was asked to make an intermediate judgement by selecting from several options, including normal chamber angle, wide chamber angle, peripheral anterior synechia and normal anterior chamber depth with an open anterior chamber angle.

The system recorded each learner's diagnostic process in a visible format to allow for self-review and reflection, as shown in Fig. 2. The diagnostic process record included the case's initial information, the clinical examinations that the learner selected for the patient, the learner's intermediate judgements after receiving the examination results and a diagnostic conclusion. Learners could practise with each case more than once.

The system generated cognitive feedback based on expert-validated reference solutions. The feedback focused on three key components of task performance. The feedback information responded to the learner's performance and identified any divergence from the reference solution for each component. As shown in Fig. 2, the learner received the following feedback: 'You missed some examinations' (feedback on the selection of the clinical examinations), 'Most of your intermediate judgements are the same with those of the experts' (feedback on the intermediate judgement) and 'Your diagnostic conclusion is different from the expert's conclusion' (feedback on the

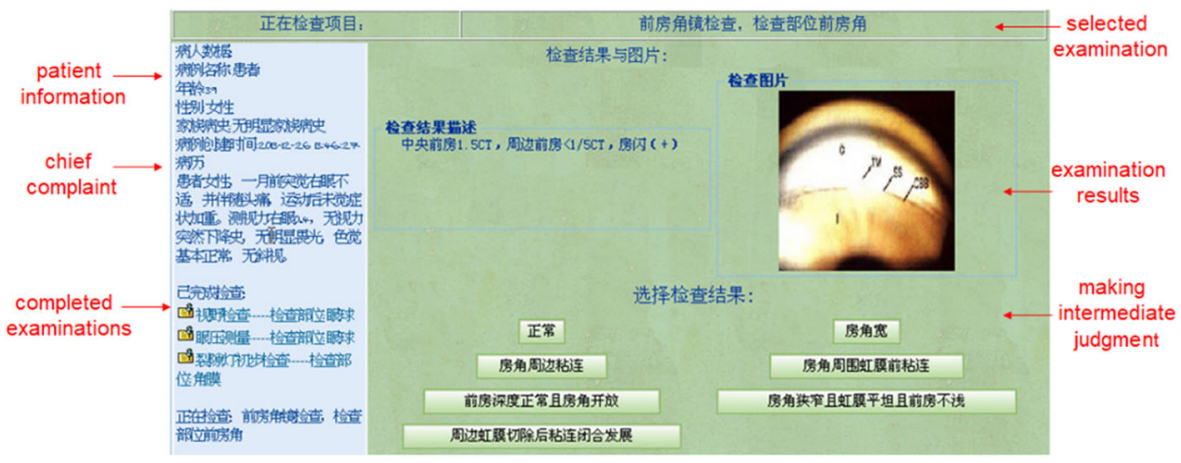

Fig. 1 Interaction with virtual patients 

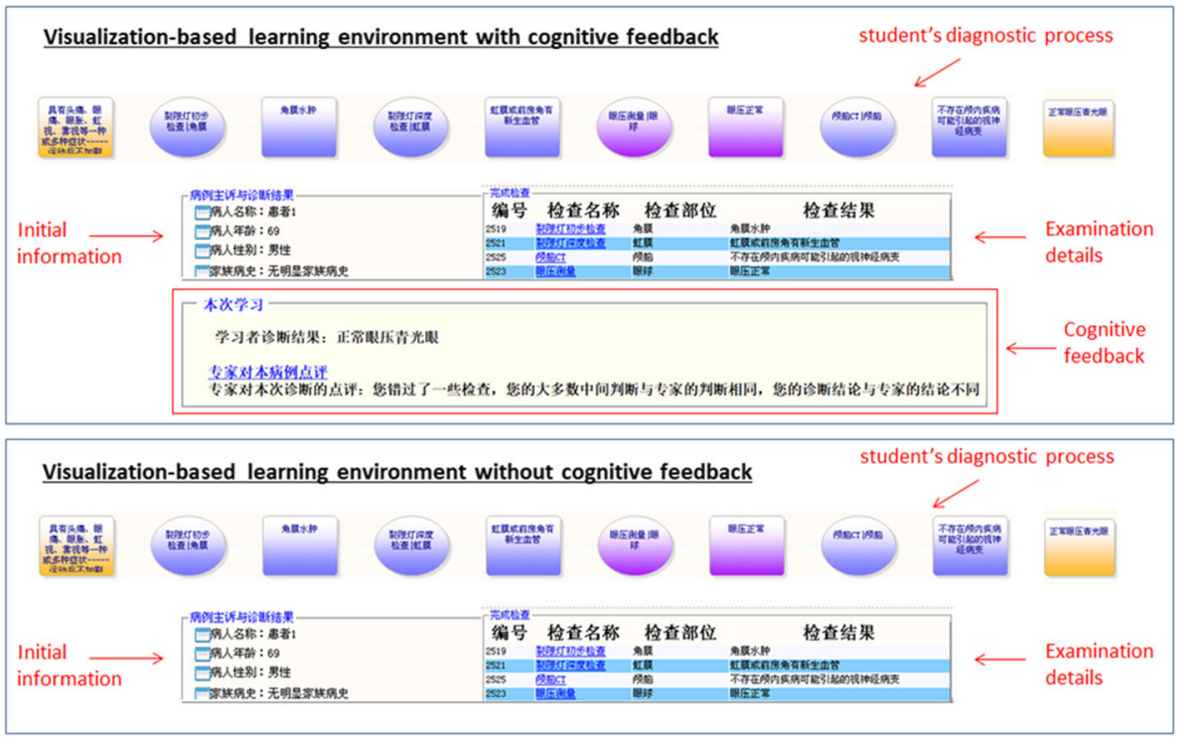

Fig. 2 Proposed learning environment with vs. without cognitive feedback

diagnostic conclusion). The learners in the experimental group could view the systemgenerated performance feedback during each round of practice. After practising a case 10 times, or when the learner's diagnostic process was $70 \%$ identical to the reference solution, the learners in both the experimental and control groups could then view the expert's case summary.

\section{Measures}

The students' subject knowledge was tested before the study to ensure that the experimental and control groups were comparable. Diagnostic performance before and after the study were assessed using clinical cases. The emotions that the students experienced during the study were measured using a questionnaire survey. Student comments on the learning programme were collected through an open-ended question in the survey.

\section{Prior Knowledge}

A pretest was administered to assess the students' subject knowledge before the study. The test comprised 10 single-choice, 10 multiple-choice, and 10 true-orfalse questions. The scores ranged from 0 (incorrect) to 1 (completely correct) for each question, with a test range of 0 to 30 , which we later scaled to range from 0 to 1. All questions were selected from the medical school's question bank, which is used to test students' knowledge on the pathophysiology of glaucoma, including its causes, symptoms and mechanisms. The domain experts endorsed the validity and appropriateness of the test questions and reference answers. Cronbach's alpha for internal consistency was .824 , confirming the reliability of the knowledge test. 


\section{Diagnostic Performance}

For both the pre- and posttest assessments of the participants' diagnostic performance, we used two different cases that the experts validated as equally difficult. The assessment was based on the degree of similarity between the student's and the expert's performance based on the diagnostic records. The assessment included three scales: (1) diagnostic conclusion, (2) clinical examinations and (3) intermediate judgements. To reach a diagnostic conclusion, learners needed to select clinical examinations to collect more information from the patient and make intermediate judgements based on the examination output over several rounds.

The performance for each of the three scales was assessed based on the number of valid items, unnecessary items and missing items in the students' diagnostic record, as specified in Formula 1:

$$
\frac{\text { Number of valid elements }}{\text { Number of valid items }+0.5 * \text { Number of unnecessary items }+0.5 * \text { Number of missing items }}
$$

which adopted Tversky's (1977) contrast formula. Valid items were elements present in the expert's diagnostic record and in the learner's diagnostic record. Unnecessary items were elements present in the learner's diagnostic record but not in the expert's diagnostic record. Missing items were elements present in the expert's diagnostic record but missing in the learner's diagnostic record.

\section{Academic Emotions}

We administered a questionnaire to measure the students' emotional experience during the study in terms of enjoyment, confidence, frustration and anxiety. The questionnaire used a 5-point Likert scale, ranging from 1 (strongly disagree) to 5 (strongly agree). We developed 12 items for each of the four subscales (enjoyment, confidence, frustration and anxiety) based on the instrument proposed by Pekrun et al. (2011) and Keller (2010). Examples of survey questions included the following: 'I really enjoyed learning with this program' (enjoyment); 'I felt confident when working on the learning tasks' (confidence); 'I felt so helpless during learning that I didn't want to continue' (frustration); and 'I was often worried about whether I could accomplish the learning task' (anxiety). Internal consistency analysis using Cronbach's alpha coefficients confirmed that the four subscales were reliable ( 0.97 for enjoyment, 0.97 for confidence, 0.94 for anxiety; 0.97 for frustration).

\section{Student Comments}

To collect student comments on the learning programme, we asked the participants the following open-ended questions: 'Do you see any benefit of the learning programme and what changes could be made to improve it?'

\section{Procedure}

The students could use the learning programme over a period of six weeks. The procedure was identical for both groups. In the first week, the participants received a 
demonstration for how to use the programme and had the opportunity to practice on the demonstration case. We then administered the knowledge and diagnostic pretests. The students began practising with the programme in the second week. They were given four weeks to complete five cases. In general, the participants paced themselves, spending, on average, about two hours per case. During the task period, the learners had no teacher involvement other than assistance with technical issues. In the sixth week, we administered the diagnostic posttest and the questionnaire. The entire procedure is outlined in Table 1.

\section{Data Analysis}

We recruited two assessors who were blind to the participants' assignment (i.e., experimental or control group) and to any information about the diagnostic tests (i.e., whether it was a pretest or posttest) to appraise the students' performance and code responses to the open-ended question. Any differences in the test results or diagnostic records were resolved by discussion and referring to reference answers or expert solutions.

We used independent $t$-tests to examine differences between the two groups in terms of (1) the students' subject knowledge and diagnostic performance before the study and (2) the level of enjoyment, confidence, frustration and anxiety that the participants experienced during the study. We used one-way analysis of covariance (ANCOVA) to examine differences between the two groups in their posttest diagnostic performance, using pretest diagnostic performance as a covariate. We calculated Cohen's $d$ effect size when significant differences were found.

The students' responses to the open-ended question were analysed to detect common themes. The analysis followed an iterative process of coding and theme generation (Krathwohl 1998). Discrepancies in emergent themes from the responses were discussed and reconciled by further consultation of the data. We then coded all participant responses based on the confirmed themes. A single response might include more than one theme since one response presented in one sentence might involve more than one issue, e.g., 'The learning system allows flexible learning and is very easy to use.'

Table 1 Procedure of the study

\begin{tabular}{|c|c|c|}
\hline \multirow[t]{2}{*}{ Time } & \multicolumn{2}{|l|}{ Activities } \\
\hline & Experimental group & Control group \\
\hline Week 1 & \multicolumn{2}{|c|}{$\begin{array}{l}\text { - Instruction and demonstration of the learning system with a sample case } \\
\text { - Pretest of subject knowledge and clinical diagnostic performance }\end{array}$} \\
\hline Week 2 - Week 5 & $\begin{array}{l}\text { Practice with five clinical cases with } \\
\text { the support of cognitive feedback }\end{array}$ & $\begin{array}{l}\text { Practice with five clinical cases without } \\
\text { the support of cognitive feedback }\end{array}$ \\
\hline Week 6 & $\begin{array}{l}\text { - Posttest of clinical diagnostic perfor } \\
\text { - Survey of emotional experience } \\
\text { - Written response to open-ended que }\end{array}$ & \\
\hline
\end{tabular}




\section{Results}

At the end of the study, 45 participants had completed all of the learning activities, comprising 25 students in the experimental group and 20 students in the control group. The other five students in the control were not available for the posttest. In the following, we present the results for the 45 participants that completed the study.

\section{Prior Knowledge}

Descriptive statistics and independent $t$-test results for prior knowledge and performance are presented in Table 2. The results indicate that the students in the experimental and control groups had no significant differences in their subject knowledge prior to the study.

\section{Diagnostic Performance}

The $t$-test results in Table 2 revealed that there were no significant differences between the two groups in all aspects of diagnostic performance prior to the study. After the study, however, the experimental group, who received the cognitive feedback treatment, outperformed the control group in all aspects of their diagnostic performance, including diagnostic conclusion, clinical examination and intermediate judgements, as shown in Table 3. The effect sizes were large for clinical examination selection (Cohen's $d=.92$ ) and intermediate judgements (Cohen's $d=.94$ ) but somewhat less pronounced for diagnostic conclusion (Cohen's $d=.24$ ).

\section{Academic Emotions}

The students in the experimental condition experienced higher levels of enjoyment and confidence and lower levels of frustration and anxiety during the study, as shown in Table 4. The students in the control condition reported close-to-moderate levels of enjoyment, confidence, frustration and anxiety during their learning process. The $t$-test results confirmed the differences between the two groups for each subscale.

Table 2 Students' subject knowledge and diagnostic performance before the study

\begin{tabular}{|c|c|c|c|c|c|c|c|c|}
\hline \multirow[t]{3}{*}{ Scales } & & \multicolumn{4}{|c|}{ Descriptive statistics } & \multicolumn{3}{|c|}{ Independent $t$-test } \\
\hline & & \multicolumn{2}{|c|}{$\begin{array}{l}\text { Experimental } \\
\text { Group }(n=25)\end{array}$} & \multicolumn{2}{|c|}{$\begin{array}{l}\text { Control } \\
\text { Group }(n=20)\end{array}$} & \multirow[b]{2}{*}{$d f$} & \multirow[b]{2}{*}{$t$} & \multirow[b]{2}{*}{$p$} \\
\hline & & Mean & $S D$ & Mean & $S D$ & & & \\
\hline \multicolumn{2}{|l|}{ Prior knowledge } & 0.47 & 0.08 & 0.47 & 0.08 & 41.562 & .234 & .816 \\
\hline \multirow{3}{*}{$\begin{array}{l}\text { Pre-Diagnostic } \\
\text { Performance }\end{array}$} & Diagnostic conclusion & .08 & .28 & .05 & .22 & 43 & .39 & .697 \\
\hline & Clinical examination & .38 & .15 & .34 & .16 & 43 & 1.17 & .410 \\
\hline & Intermediate Judgement & .18 & .17 & .15 & .18 & 43 & .63 & .593 \\
\hline
\end{tabular}


Table 3 ANCOVA of students' diagnostic performance after the study

\begin{tabular}{|c|c|c|c|c|c|c|c|c|c|}
\hline \multirow[t]{2}{*}{ Scales } & \multicolumn{3}{|c|}{$\begin{array}{l}\text { Experimental } \\
\text { Group }(n=25)\end{array}$} & \multicolumn{3}{|c|}{$\begin{array}{l}\text { Control Group } \\
(\mathrm{n}=20)\end{array}$} & \multirow[t]{2}{*}{$p$} & \multirow[t]{2}{*}{$F(1,43)$} & \multirow[t]{2}{*}{ Cohen's $d$} \\
\hline & Mean & $S D$ & $\begin{array}{l}\text { Adjusted } \\
\text { Mean }\end{array}$ & Mean & $S D$ & $\begin{array}{l}\text { Adjusted } \\
\text { Mean }\end{array}$ & & & \\
\hline Diagnostic conclusion & .400 & .500 & .401 & .350 & .489 & .349 & $.033 *$ & .118 & .24 \\
\hline Clinical examination & .667 & .188 & 667 & .454 & .238 & .454 & $.002 * *$ & 10.800 & .92 \\
\hline $\begin{array}{l}\text { Intermediate } \\
\text { judgement }\end{array}$ & .541 & .203 & .538 & .295 & .213 & .299 & $.0005 * * *$ & 15.087 & .94 \\
\hline
\end{tabular}

$* p<.05 ; * * p<.01 ; * * * p<.001$

\section{Student Comments on the Learning Programme}

Table 5 displays the themes by frequency for both groups. Illustrative examples are verbatim quotations selected from the participant responses.

Many of the students in both the experimental and control groups commented that they enjoyed the flexibility of the online learning programme, as it allowed them to learn at their own pace, without time or space constraints. The students in both groups also indicated that the learning system was easy to use.

Compared with those in the control group, more students in the experimental group reported that the practice-oriented learning programme was helpful for developing professional competence in clinical diagnostics. The students in the experimental group also indicated that the learning programme fostered self-directed learning by allowing them to review their diagnostic records in a convenient visual format and to reflect on discrepancies between their solutions and the expert solution. They also suggested that the learning programme include more cases for practice. In contrast, the students in the control group were more likely to report having difficulties completing the tasks on their own and to request guidance or support.

In addition, the participants in both groups suggested that more learning resources be incorporated into the learning programme and a few reported that they had experienced problems accessing the learning system when the network speed was slow.

Table 4 Descriptive statistics and independent $t$-test results on academic emotion

\begin{tabular}{|c|c|c|c|c|c|c|c|}
\hline \multirow[t]{3}{*}{ Scales } & \multicolumn{4}{|c|}{ Descriptive statistics } & \multicolumn{3}{|c|}{ Independent $t$-test } \\
\hline & \multicolumn{2}{|c|}{ Experimental Group $(n=25)$} & \multicolumn{2}{|c|}{ Control Group $(\mathrm{n}=20)$} & & & \\
\hline & Mean & $S D$ & Mean & $S D$ & $t$ & $d f$ & $p$ \\
\hline Enjoyment & 4.08 & .99 & 3.52 & .95 & 1.932 & 43 & $.048 *$ \\
\hline Confidence & 4.13 & .96 & 3.38 & 1.04 & 2.508 & 43 & $.016^{*}$ \\
\hline Frustration & 1.75 & .95 & 2.65 & .81 & -2.737 & 43 & $.007 * *$ \\
\hline Anxiety & 1.85 & 1.12 & 2.58 & .83 & -2.164 & 43 & $.009 * *$ \\
\hline
\end{tabular}

$* p<.05 ; * * p<.01$ 


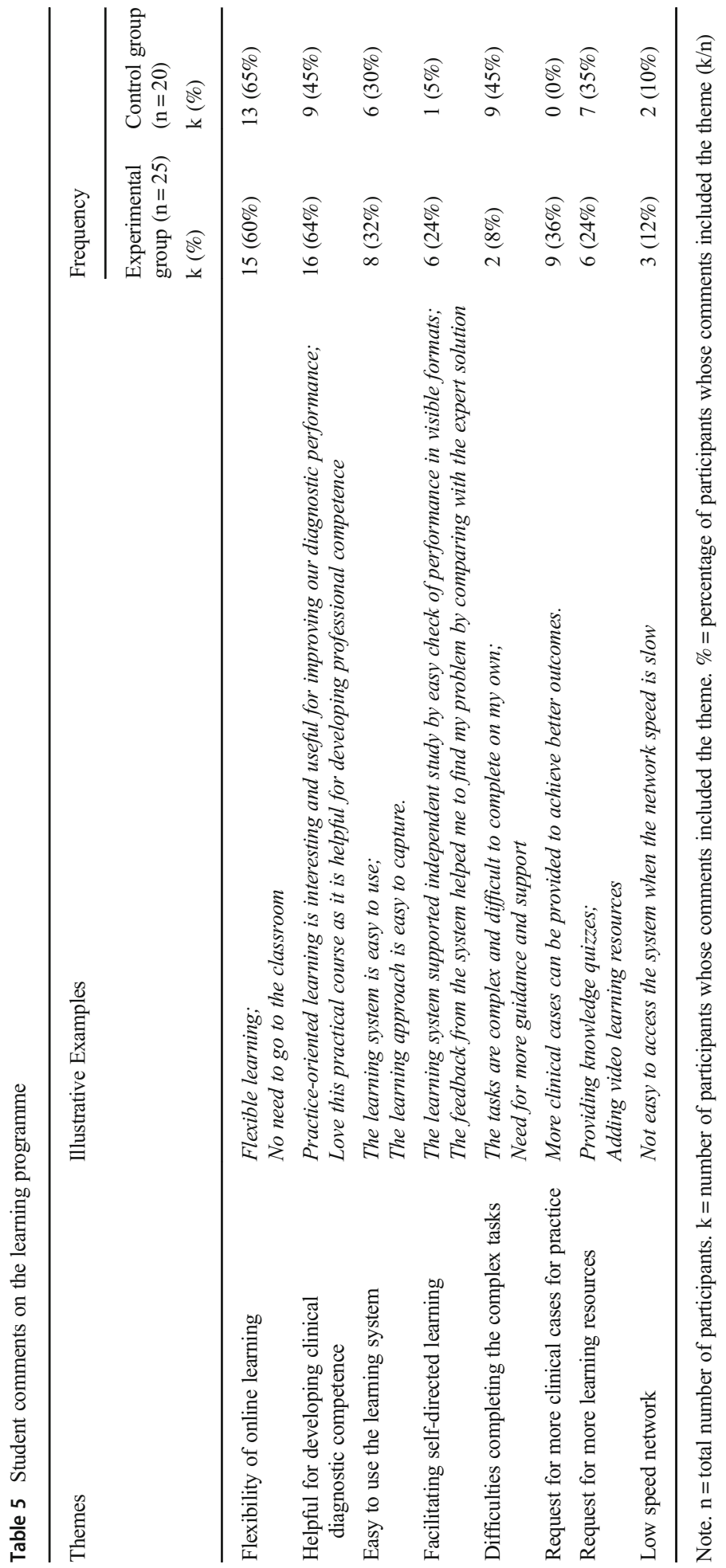




\section{Discussion}

\section{Effects on Task Performance}

Incorporating cognitive feedback in an online, practice-oriented learning environment was found to positively influence learners' diagnostic performance. This echoes prior studies' findings that problem-solving performance can be enhanced when performance errors are immediately identified and discussed (Colvin 2008; Kuhn 2002). Other related research has shown that the support of expert knowledge can improve students' ability to differentiate relevant and irrelevant information as evidence to justify a diagnosis (Lajoie et al. 2001).

Our proposed cognitive feedback approach was designed to facilitate reflective practice by providing learners with information about their performance on each key component of the task (i.e., selecting clinical examinations, making intermediate judgements, and reaching diagnostic conclusions). The positive effects of this approach are consistent with Mamede et al.'s (2008) finding that incorporating structured and explicit reflection can have a positive influence on medical students' diagnostic competence. The finding is also consistent with previous research that demonstrated the positive effects of providing feedback emphasizing structural features of complex tasks, which enable learners to recognize the structural features in future tasks (Corbalan et al. 2009; Mory 2003).

The experimental group in this study outperformed the control in selecting clinical examinations, making intermediate judgements, and reaching a diagnostic conclusion. The cognitive feedback was found to have a larger effect on the students' selection of clinical examinations and intermediate judgements than on their diagnostic conclusions. One plausible explanation for this finding is that medical students can reach a correct diagnostic conclusion even with errors in their intermediate judgements and selection of clinical examinations. This is supported by research findings that novices tend to have less coherent solutions to problems (Van de Wiel et al. 1999); similarly, students reaching an accurate diagnosis may not fully understand the mechanism underlying the process (Eva 2005). Our findings suggest that offering cognitive feedback throughout the task process has the potential to address this issue.

\section{Effects on Academic Emotion}

The practice-oriented, feedback-supported learning environment approach that we proposed also showed promising effects on learners' enjoyment and confidence while reducing their frustration and anxiety during the learning process. Clinical diagnosis is a complex and challenging practice and novice learners might endure frustration and anxiety as they develop competence. Providing cognitive feedback has the potential to reduce learners' negative emotions and improve their confidence to complete the complex task at hand. The results echo the findings of previous studies on the affective effects of feedback on task performance (Azevedo and Bernard 1995; Corbalan et al. 2009; Keller 1983; Vollmeyer and Rheinberg 2005).

The positive effects of cognitive feedback on the participants' diagnostic performance and emotions were consistent with their comments about the learning programme. Whilst the participants in the experimental condition experienced high levels 
of confidence and enjoyment during the learning process, they also commented on the benefit of cognitive feedback in supporting self-directed learning and expressed a desire to practice with more cases. This finding is consistent with research indicating that confidence is crucial to self-directed learning and practice because it influences the degree to which learners engage and persevere when faced with challenging tasks (Schraw et al. 2006). Whilst the students in both groups enjoyed the benefit of practice-oriented learning and the flexibility of online learning, students in the control group expressed the need for more support and guidance to complete the tasks, which was consistent with the low levels of confidence that they experienced through the learning process.

\section{Conclusions}

Learning through practice with clinical cases plays an important role in the development of medical students' diagnostic competence. It offers an opportunity for learners to identify their knowledge or skill gaps and to determine learning goals for improvement, which is essential for continuing professional development. Although self-reflection can benefit students' learning and diagnostic competence, it is not easy for novice learners to develop expert-like performance through self-reflection alone. Conversely, valid and timely cognitive feedback on clinical performance is considered a cornerstone of effective clinical education and professional development; however, seeking constant feedback or supervision from experts during practice can also be highly impractical.

This study investigated the design and effects of cognitive feedback for practiceoriented learning in an online environment. Reflective practice with simulated cases is facilitated not only through a visualisation of learners' diagnostic processes to facilitate self-reflection, but also by providing students with cognitive feedback on the gap between their performance and expert performance on a set of key components of the task. The findings of the study show that performance feedback on each key component of the task has promising effects on improving learners' diagnostic performance and reducing feelings of anxiety and frustration during practice. In addition to enhancing task performance, the feedback on key components of the task can improve learners' understanding of the mechanisms driving the diagnostic process.

The findings contribute to our knowledge of how cognitive feedback can be designed in a way that improves practice-oriented learning with complex diagnostic tasks with a view to developing expert-like performance as well as understanding the mechanism underlying the complex task. Although the present study selected glaucoma diagnosis as the task domain, the proposed approach has a potential to improve practice-oriented learning with complex diagnostic tasks in other domains, such as diagnosis of other diseases, fault diagnosis of machines, and so on.

This study has some limitations. First, findings from the relatively small number of participants may not be sufficient to generalise to a broader population. Second, findings from one subject domain do not necessarily generalise to other domains. In addition, there may have been cultural influences affecting the findings, as all of the participants shared a national background. Also, the two-group pretest-posttest design might possibly suffer from the pretesting effect, which may jeopardize external validity. Further research is needed to address these limitations and to investigate how this learning approach translates 
to clinical performance with real-life cases. Given the dialogic and iterative nature of feedback, further research will need to explore the incorporation of novice-expert dialogue and ongoing interaction within learning activities.

Acknowledgement This research is supported by the General Research Fund from the Research Grants Council of the Hong Kong SAR Government (Project No. 17201415) and the Seeding Fund for Basic Research from the University of Hong Kong (Project No. 201811159019). The authors would thank Professor David Carless for his advice on the review of the feedback literacy.

\section{Appendix. Survey instruments}

\section{Perceived Enjoyment}

I really enjoyed learning with this programme. (Pekrun et al. 2011 \& Keller 2010). I got excited about learning a lot from this course. (Pekrun et al. 2011 \& Keller 2010). I am satisfied with what I have learnt from this programme. (Pekrun et al. 2011 \& Keller 2010).

\section{Perceived Confidence}

I felt confident when working on the learning tasks. (Pekrun et al. 2011 \& Keller 2010). I felt that I was able to complete the tasks without extra help. (Pekrun et al. 2011 \& Keller 2010).

I am confident that my performance in these tasks was good. (Pekrun et al. 2011 \& Keller 2010).

\section{Perceived Frustration}

I felt so helpless during the learning process that I didn't want to continue. (Pekrun et al. 2011) I felt discouraged during the learning process. (Pekrun et al. 2011)

I felt frustrated because I was unable to cope with the tasks. (Pekrun et al. 2011)

\section{Perceived Anxiety}

I was often worried about whether I could accomplish the learning task. (Pekrun et al. 2011) I felt anxious while working on the tasks. (Pekrun et al. 2011)

The learning programme made me sweat. (Pekrun et al. 2011)

\section{References}

Ajjawi, R., \& Boud, D. (2018). Examining the nature and effects of feedback dialogue. Assessment \& Evaluation in Higher Education, 43(7), 1106-1119.

Archer, J. C. (2010). State of the science in health professional education: Effective feedback. Medical Education, 44(1), 101-108.

Azevedo, R., \& Bernard, R. M. (1995). A meta-analysis of the effects of feedback in computer-based instruction. Journal of Educational Computing Research, 13, 111-127. 
Banning, M. (2008). The think aloud approach as an educational tool to develop and assess clinical reasoning in undergraduate students. Nurse Education Today, 28(1), 8-14.

Barrows, H. S. (1996). Problem-based learning in medicine and beyond: A brief overview. New Directions for Teaching and Learning, 68, 3-12.

Bing-You, R., Hayes, V., Varaklis, K., Trowbridge, R., Kemp, H., \& McKelvy, D. (2017). Feedback for learners in medical education: What is known? A scoping review. Academic Medicine, 92(9), 1346-1354.

Bok, H. G. J., Teunissen, P. W., Spruijt, A., Fokkema, J. P. I., van Beukelen, P., Jaarsma, D. A. D. C., \& van der Vleuten, C. P. M. (2013). Clarifying students' feedback-seeking behaviour in clinical clerkships. Medical Education, 47(3), 282-291.

Boldrini, E., \& Cattaneo, A. (2014). Scaffolding collaborative reflective writing in a VET curriculum. Vocations and Learning, 7, 145-165.

Bordage, G. (1999). Why did I miss the diagnosis? Some cognitive explanations and educational implications. Academic Medicine, 74(10), S138-S143.

Boud, D., \& Molloy, E. (2013). Rethinking models of feedback for learning: The challenge of design. Assessment \& Evaluation in Higher Education, 38(6), 698-712.

Boud, B., \& Walker, D. (1990). Making the most of experience. Studies in Continuing Education, 12(2), 61-80.

Branch, W. T., \& Paranjape, A. (2002). Feedback and reflection: Teaching methods for clinical settings. Academic Medicine, 77(12), 1185-1188.

Butler, D. L., \& Winne, P. H. (1995). Feedback and self-regulated learning: A theoretical synthesis. Review of Educational Research, 65, 245-281.

Carless, D., \& Boud, D. (2018). The development of student feedback literacy: Enabling uptake of feedback. Assessment \& Evaluation in Higher Education, 43(8), 1315-1325.

Chiu, D. K. W., Lin, D. T. T., Kafeza, E., Wang, M., Hu, H., Hu, H., \& Zhuang, Y. (2010). Alert-based disaster notification and resource allocation. Information Systems Frontiers, 12(1), 29-47.

Colvin, G. (2008). Talent is overrated: What really separates world-class performers from everybody else. New York, NY: Portfolio.

Cook, D. A., \& Triola, M. M. (2009). Virtual patients: A critical literature review and proposed next steps. Medical Education, 43(4), 303-311.

Corbalan, G., Kester, L., \& Van Merriënboer, J. J. G. (2009). Dynamic task selection: Effects of feedback and learner control on efficiency and motivation. Learning and Instruction, 19(6), 455-465.

Delany, C., \& Golding, C. (2014). Teaching clinical reasoning by making thinking visible: An action research project with allied health educators. BMC Medical Education, 14, 20.

Dewey, J. (1938). Experience and education. New York, NY: Simon \& Schuster.

D'Mello, S., \& Graesser, A. (2012). Dynamics of affective states during complex learning. Learning and Instruction, 22(2), 145-157.

Durning, S., Artino Jr., A. R., Pangaro, L., van der Vleuten, C. P. M., \& Schuwirth, L. (2011). Context and clinical reasoning: Understanding the perspective of the expert's voice. Medical Education, 45(9), 927-938.

Elstein, S. A., Shulman, L. S., \& Sprafka, S. A. (1978). Medical problem solving: An analysis of clinical reasoning. Cambridge, MA: Harvard University Press.

Ericsson, K. A. (2008). Deliberate practice and acquisition of expert performance: A general overview. Academic Emergency Medicine, 15(11), 988-994.

Eva, K. W. (2005). What every teacher needs to know about clinical reasoning. Medical Education, 39(1), 98-106.

Eva, K. W., \& Regehr, G. (2005). Self-assessment in the health professions: A reformulation and research agenda. Academic Medicine, 80(10), S46-S54.

Evans, C. (2013). Making sense of assessment feedback in higher education. Review of Educational Research, $83(1), 70-120$.

Henderson, A. J., Alexander, H., Haywood, A., Stapleton, P., Cooke, M., Patterson, E., et al. (2010). Promoting and providing expert guidance in work-intensive clinical settings. Vocations and Learning, 3, 141-156.

Kassirer, J. P. (2010). Teaching clinical reasoning: Case-based and coached. Academic Medicine, 85(7), 1118-1124.

Keller, J. M. (2010). Motivational design for learning and performance: The ARCS model approach. Boston, MA: Springer.

Keller, J. M. (1983). Motivational design of instruction. In C. M. Reigeluth (Ed.), Instructional theories and models: An overview of their current status (pp. 383-434). Hillsdale, NJ: Erlbaum.

Kolb, D. (1984). Experiential learning. Experience as the source of learning and development. Englewood Cliffs, NJ: Prentice Hall.

Krathwohl, D. R. (1998). Methods of educational and social science research: An integrated approach (2nd ed.). New York: Longman.

Kuhn, G. J. (2002). Diagnostic errors. Academic Emergency Medicine, 9(7), 740-750. 
Lajoie, S. P., Lavigne, N. C., Guerrera, C., \& Munsie, S. D. (2001). Constructing knowledge in the context of BioWorld. Instructional Science, 29(2), 155-186.

Mamede, S., Van Gog, T., Moura, A. S., de Faria, R. M. D., Peixoto, J. M., Rikers, R., M, J. P., \& Schmidt, H. G. (2012). Reflection as a strategy to foster medical students' acquisition of diagnostic competence. Medical Education, 46(5), 464-472.

Mamede, S., \& Schmidt, H. G. (2004). The structure of reflective practice in medicine. Medical Education, 38(12), 1302-1308.

Mamede, S., Schmidt, H. G., \& Penaforte, J. C. (2008). Effects of reflective practice on the accuracy of medical diagnoses. Medical Education, 42(5), 468-475.

Mann, K., Gordon, J., \& MacLeod, A. (2009). Reflection and reflective practice in health professions education: A systematic review. Advances in Health Sciences Education, 14(4), 595-621.

Molloy, E. (2009). Time to pause: Giving and receiving feedback in clinical education. In C. Delany \& E. Molloy (Eds.), Clinical education in the health professions (pp. 128-145). Chatswood, NSW: Elsevier.

Moon, J. A. (1999). Reflection in learning and professional development: Theory and practice. London, UK: Kogan Page.

Mory, E. H. (2003). Feedback research revisited. In D. H. Jonassen (Ed.), Handbook of research on educational communications and technology (pp. 745-783). Mahwah, NJ: Erlbaum.

Nelson, M. M., \& Schunn, C. D. (2009). The nature of feedback: How different types of peer feedback affect writing performance. Instructional Science, 37(4), 375-401.

Norman, G. (2005). Research in clinical history: Past history and current trends. Medical Education, 39, 418-427.

Pekrun, R., Goetz, T., Frenzel, A. C., Barchfeld, P., \& Perry, R. P. (2011). Measuring emotions in students' learning and performance: The achievement emotions questionnaire (AEQ). Contemporary Educational Psychology, 36(1), 36-48.

Peng, J., Wang, M., Sampson, D., \& van Merrienboer, J. (2019). Using a visualization-based and progressive learning environment as a cognitive tool for learning computer programming. Australasian Journal of Educational Technology, 35(2), 52-68.

Phelps, E. A. (2006). Emotion and cognition: Insights from studies of the human amygdala. Annual Review of Psychology, 57, 27-53.

Postma, T. C., \& White, J. G. (2015). Developing clinical reasoning in the classroom - Analysis of the 4C/ID model. European Journal of Dental Education, 19(2), 74-80.

Ruiz, J. G., Mintzer, M. J., \& Leipzig, R. M. (2006). The impact of e-learning in medical education. Academic Medicine, 81(3), 207-212.

Schmidt, H. G., \& Mamede, S. (2015). How to improve the teaching of clinical reasoning: A narrative review and proposal. Medical Education, 49(10), 961-973.

Schön, D. A. (1983). The reflective practitioner: How professionals think in action. New York, NY: Basic Books.

Schraw, G., Crippen, K. J., \& Hartley, K. (2006). Promoting self-regulation in science education: Metacognition as part of a broader perspective on learning. Research in Science Education, 36(1/2), 111-139.

Schutz, P. A., \& DeCuir, J. T. (2002). Inquiry on emotions in education. Educational Psychologist, 37(2), $125-134$.

Shute, V. J. (2008). Focus on formative feedback. Review of Educational Research, 78, 153-189.

Sutton, P. (2012). Conceptualizing feedback literacy: Knowing, being, and acting. Innovations in Education and Teaching International, 49(1), 31-40.

Telio, S., Ajjawi, R., \& Regehr, G. (2015). The "educational Alliance" as a framework for Reconceptualizing feedback in medical education. Academic Medicine, 90(5), 609-614.

Tversky, A. (1977). Features of similarity. Psychological Review, 84(4), 327-352.

Van de Wiel, M. W. J., Boshuizen, H. P. A., Schmidt, H. G., \& Schaper, N. C. (1999). The explanation of clinical concepts by expert physicians, clerks, and advanced students. Teaching and Learning in Medicine, 11(3), 153-163.

Van Merrienboer, J. J. G., \& Kirschner, P. A. (2018). Ten steps to complex learning: A systematic approach to four-component instructional design. New York, NY: Routledge.

Van Merriënboer, J. J. G., \& Sweller, J. (2010). Cognitive load theory in health professional education: Design principles and strategies. Medical Education, 44(1), 85-93.

Vollmeyer, R., \& Rheinberg, F. (2005). A surprising effect of feedback on learning. Learning and Instruction, 15, 589-602.

Wang, M. (2018). E-learning in the workplace: A performance-oriented approach beyond technology. Switzerland: Springer.

Wang, M., Jia, H., Sugumaran, V., Ran, W., \& Liao, J. (2011). A web-based learning system for software test professionals. IEEE Transactions on Education, 54(2), 263-272. 
Wang, M., Yuan, B., Kirschner, P. A., Kushniruk, A., \& Peng, J. (2018). Reflective learning with complex problems in a visualization-based learning environment with expert support. Computers in Human Behavior, 87, 406-415.

Williams, R. G., Klamen, D. L., White, C. B., Petrusa, E., Fincher, R. M. E., Whitfield, C. F., et al. (2011). Tracking development of clinical reasoning ability across five medical schools using a progress test. Academic Medicine, 86(9), 1148-1154.

Wu, B., \& Wang, M. (2012). Integrating problem solving and knowledge construction through dual mapping. Knowledge Management \& E-Learning, 4(3), 248-257.

Wu, B., Wang, M., Grotzer, T. A., Liu, J., \& Johnson, J. M. (2016). Visualizing complex processes using a cognitive-mapping tool to support the learning of clinical reasoning. BMC Medical Education, 16, 216.

Wigton, R. S., Poses, R. M., Collins, M., \& Cebul, R. D. (1990). Teaching old dogs new tricks: Using cognitive feedback to improve physicians' diagnostic judgments on simulated cases. Academic Medicine, 65(9), S5-S6.

Yuan, B., Wang, M., Kushniruk, S. W., \& Peng, J. (2016). Design of a computer-based learning environment to support diagnostic problem solving towards expertise development. Knowledge Management \& ELearning, 8(4), 540-549.

Publisher's Note Springer Nature remains neutral with regard to jurisdictional claims in published maps and institutional affiliations.

Dr. Bei Yuan is Lecturer at Zhongshan Teachers Education Institute, China. She is also a postdoctoral researcher at the Laboratory for Knowledge Management \& E-Learning (KM\&EL) in the Faculty of Education, The University of Hong Kong.

Dr. Minhong (Maggie) Wang currently holds the position of Eastern Scholar Chair Professor at East China Normal University. She is Professor and Director of the Laboratory for Knowledge Management \& E-Learning (KM\&EL) in the Faculty of Education, The University of Hong Kong.

Dr. Jeroen van Merriënboer is Professor and Research Director of the Graduate School of Health Professions Education at the Maastricht University, The Netherlands.

Dr. Xu Tao is an ophthalmologist at the Department of Ear, Nose and Throat at the Xiangtan Central Hospital, China.

Dr. Andre Kushniruk is Professor at the School of Health Information Science, University of Victoria, Canada.

Dr. Jun Peng is Assistant Professor at the School of Education, City University of Macau. He is also a postdoctoral researcher at the Laboratory for Knowledge Management \& E-Learning (KM\&EL) in the Faculty of Education, The University of Hong Kong.

\section{Affiliations}

\section{Bei Yuan ${ }^{1,2} \cdot$ Minhong Wang ${ }^{3,2} \cdot$ Jeroen van Merriënboer ${ }^{4} \cdot \mathrm{Xu} \mathrm{Tao}^{5} \cdot$ Andre $^{2}$ Kushniruk $^{6}$. Jun Peng ${ }^{7,2}$}

1 Zhongshan Teachers Education Institute, Zhongshan, China

2 KM\&EL Lab, Faculty of Education, The University of Hong Kong, Hong Kong, China

3 Department of Educational Information Technology, East China Normal University, Shanghai, China

4 Graduate School of Health Professions Education, Maastricht University, Maastricht, The Netherlands

5 Department of Ear, Nose and Throat, Xiangtan Central Hospital, Xiangtan, China

6 School of Health Information Science, University of Victoria, Victoria, Canada

7 School of Education, City University of Macau, Macau, China 